\title{
Erratum to: Analysis of a new two-lane lattice hydrodynamic model with consideration of the global average flux
}

\author{
Geng Zhang · Di-Hua Sun · Wei-Ning Liu
}

Published online: 28 December 2015

(C) Springer Science+Business Media Dordrecht 2015

Erratum to: Nonlinear Dyn (2015) 81:1623-1633

DOI 10.1007/s11071-015-2095-0

The authors' first affiliation was incomplete in the original publication. It is correct as shown in this erratum.

The online version of the original article can be found under doi:10.1007/s11071-015-2095-0.

G. Zhang · D.-H. Sun · W.-N. Liu

Key Laboratory of Dependable Service Computing in Cyber Physical Society of Ministry of Education,

Chongqing University, Chongqing 400044, China

G. Zhang · D.-H. Sun $(\varangle)$

College of Automation, Chongqing University,

Chongqing 400044, China

e-mail: d3sun@163.com

W.-N. Liu

College of Computer Science, Chongqing University,

Chongqing 400044, China 